\title{
Enhanced neuronal Met signalling levels in ALS mice delay disease onset
}

\author{
M Genestine ${ }^{1,5}$, E Caricati ${ }^{1,4,5}$, A Fico ${ }^{1,5}$, S Richelme ${ }^{1}$, H Hassani ${ }^{1}$, C Sunyach ${ }^{2}$, F Lamballe ${ }^{1}$, GC Panzica ${ }^{3}$, B Pettmann ${ }^{2}$, \\ F Helmbacher ${ }^{1}$, C Raoul ${ }^{2}$, F Maina ${ }^{*, 1,6}$ and R Dono ${ }^{*, 1,6}$
}

Signalling by receptor tyrosine kinases (RTKs) coordinates basic cellular processes during development and in adulthood. Whereas aberrant RTK signalling can lead to cancer, reactivation of RTKs is often found following stress or cell damage. This has led to the common belief that RTKs can counteract degenerative processes and so strategies to exploit them for therapy have been extensively explored. An understanding of how RTK stimuli act at cellular levels is needed, however, to evaluate their mechanism of therapeutic action. In this study, we genetically explored the biological and functional significance of enhanced signalling by the Met RTK in neurons, in the context of a neurodegenerative disease. Conditional met-transgenic mice, namely Rosa26 ${ }^{\text {LacZ-stop-Met }}$, have been engineered to trigger increased Met signalling in a temporal and tissue-specific regulated manner. Enhancing Met levels in neurons does not affect either motor neuron (MN) development or maintenance. In contrast, increased neuronal Met in amyotrophic lateral sclerosis (ALS) mice prolongs life span, retards MN loss, and ameliorates motor performance, by selectively delaying disease onset. Thus, our studies highlight the properties of RTKs to counteract toxic signals in a disease characterized by dysfunction of multiple cell types by acting in MNs. Moreover, they emphasize the relevance of genetically assessing the effectiveness of agents targeting neurons during ALS evolution.

Cell Death and Disease (2011) 2, e130; doi:10.1038/cddis.2011.11; published online 17 March 2011

Subject Category: Neuroscience

Signalling by receptor tyrosine kinases (RTKs) is involved in cell communication events regulating tissue morphogenesis during development and tissue homeostasis during adulthood. ${ }^{1}$ In vivo, RTK signalling levels vary according to a number of parameters, such as RTK expression levels, ligand availability, action of positive/negative signalling regulators, and components of the signalling cascade. The levels of RTK signalling determine qualitatively different biological outcomes. $^{2}$ Given the multiple roles of RTKs in coordinating basic biological processes, modulating their activation levels is a means of achieving different cellular responses in normal processes and in pathological conditions. Notably, RTK activation is tightly regulated in healthy adult tissues as aberrant signalling in susceptible cells can cause pathologies, such as cancer. ${ }^{1,3}$ Conversely, studies on degenerative diseases have shown that following stress or cell damage there is nearly always a reactivation of RTK signalling, coinciding with periods of active fight for survival/repair. ${ }^{4,5}$ For example, genetic analysis of RTK functions in neurodegenerative processes have demonstrated their requirement for repair of damaged tissues. ${ }^{4}$ In contrast, studies on cultured cells and on animal models have shown that symptoms linked to degenerative diseases can be ameliorated when activation of appropriate RTKs is achieved through exogenous ligand administration. ${ }^{4,6}$ However, it is still not clear to which extent levels of remobilized endogenous RTKs are limiting for effective neuronal repair in disease CNS.

Over the last years, a regional and temporal map of RTKdependency has emerged, suggesting that an appropriate enhancement of RTK signalling might be beneficial to efficiently counteract disease onset and progression. This issue is particularly relevant for neurodegenerative diseases, such as amyotrophic lateral sclerosis (ALS), an adult onset motor neuron (MN) disease caused by pathological processes occurring in both neuronal and non-neuronal cells. ${ }^{7}$ ALS involves progressive degeneration of upper and lower MNs, culminating in muscle wasting, and death mostly due to respiratory failure. Although the aetiology of most cases remains unknown, $10-20 \%$ of familial ALS is caused by mutations in the superoxide dismutase1 (SOD1) gene.

\footnotetext{
${ }^{1}$ Developmental Biology Institute of Marseille-Luminy (IBDML), UMR 6216, CNRS - Inserm - Université de la Méditerranée, Campus de Luminy-Case 907, Marseille Cedex 09, France; ${ }^{2}$ Inserm-Avenir Team, The Mediterranean Institute of Neurobiology, Marseille, France and ${ }^{3}$ Departments of Anatomy, Pharmacology, and Forensic Medicine, Torino, Italy

${ }^{*}$ Corresponding author: F Maina or R Dono, Developmental Biology Institute of Marseille-Luminy (IBDML), UMR 6216, CNRS - Inserm - Université de la Méditerranée, Campus de Luminy-Case 907, Marseille Cedex 09, 13288, France. Tel: + 3349126 9769; Fax: + 3349126 9244; E-mail: flavio.maina@ ibdml.univmed.fr (F Maina) or rosanna.dono@ibdml.univmed.fr (R Dono)

${ }^{4}$ Current address: Departments of Anatomy, Pharmacology, and Forensic Medicine, c.so M.D’Azeglio 2, 10126 Torino, Italy.

${ }^{5}$ These authors equally contributed to the work.

${ }^{6}$ Shared last authors.

Keywords: RTK signalling; conditional transgenesis; neuro-degenerative disease; HGF/Met; ALS

Abbreviations: RTK, receptor tyrosine kinase; MN, motor neuron; ALS, amyotrophic lateral sclerosis; CMV, cytomegalovirus; GFAP, glial fibrillary acidic protein; VAChT, vesicular-acetylcholie-transporter; SOD, superoxide dismutase; NMJ, neuro-muscular junction

Received 09.9.10; revised 11.1.11; accepted 01.2.11; Edited by A Verkhraski
} 
Consistently, transgenic mice expressing the mutant forms of human SOD1 recapitulate a number of ALS symptoms and have been instrumental in evaluating the molecular and cellular events underlying ALS pathology. ${ }^{7}$ Moreover, genetic and cell biological studies based on the differential expression of mutant SOD1 in distinct cell types have demonstrated that although death of MNs causes ALS symptoms, the disease also renders other cells, such as astrocytes and microglia, dysfunctional. Thus, MN loss, in addition to a cell-autonomous origin, is also triggered by noncell-autonomous defects involving toxicity of other unhealthy cells. ${ }^{8,9}$ Notably, these different cell types play distinct roles in ALS pathogenesis. Damage within MNs is primarily associated with disease onset and its early progression phase, whereas damage within microglia and astrocytes accelerates MN degeneration and ALS progression. ${ }^{8-12}$ The recognition that multiple cell types determine ALS evolution has boosted the need to understand the relative contribution of providing beneficial signals to different cell types involved in the disease.

Among several strategies to alleviate ALS symptoms, a major hope has been placed on the ability of trophic factors, acting on $\mathrm{MN}$ in culture or during development, ${ }^{4,7}$ to activate endogenous RTKs. Initial results were disappointing as infusion of specific trophic factors had little or no beneficial effects. The weakness of these approaches appeared to be inadequate delivery of these factors to the right cells. This possibility was further supported by genetic studies assessing growth factor efficacy depending on the delivery site. ${ }^{13,14}$ Therefore, understanding the relative contribution of enhancing RTK signalling in distinct cell types is needed to further clarify the ALS biology and to evaluate how beneficial signals should be delivered for therapy.

In this study, we assessed the biological and functional significance of enhanced signalling, above endogenous levels, downstream of the Met RTK specifically in neurons during neuro-degenerative diseases, such as ALS. A number of features makes the Met receptor of special interest to address RTK signalling levels during neuro-degeneration. ${ }^{15,16}$ During development, activation of the Met receptor by its ligand HGF regulates $\mathrm{MN}$ fate at multiple levels, including identity acquisition, axonal growth, and survival. ${ }^{2,17-20}$ During injury, HGF is able to enhance regeneration of the lesioned spinal cord and of crushed peripheral nerves. ${ }^{21,22}$ Intracerebral delivery or transgenic-mediated neuronal expression of HGF in mutant SOD1 animal models acts simultaneously on different dysfunctional cell types. ${ }^{23,24}$ However, the contribution of enhancing Met signalling uniquely in neurons and its relative impact on ALS onset and progression remains to be established. To enhance Met signalling above a threshold level in a temporal and tissue-specific manner, we generated conditional met transgenic mice using the cre-loxP system. Here, we show that transgene-mediated neuronal expression of the Met RTK in $S O D 1^{G 93 A}$ mice selectively delays disease onset, without slowing down its progression. Our findings show that boosting RTK signalling in a cell-type-restricted manner can have a distinct beneficial impact in counteracting the processes underlying the evolution of neurodegenerative diseases.

\section{Results}

Generation of conditional Rosa26 $6^{\text {LacZ-stop-Met }}$ transgenic mice. To enhance Met signalling levels in a temporally and spatially regulated manner, we generated mice carrying a conditional mouse-human chimeric met transgene $\left(m^{t g} t^{t g}\right)$. In particular, we engineered a mouse strain in which a cytomegalovirus (CMV)-enhancer/ $\beta$-actinpromoter controls the expression of a floxed- $\beta$-geo-reporter gene followed by a met ${ }^{t g}$. Such a strategy was chosen to keep the met $^{\text {tg }}$ silent, unless the stop cassette is excised by cre-mediated recombination. To avoid integration site effects and favour loxP-site accessibility, the construct was inserted into the Rosa26 locus (Rosa26 ${ }^{\text {LacZ-stop-Met, referred to }}$

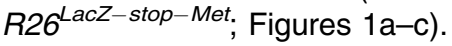

To specifically gain expression in neural cells, we crossed the $R 26^{L a c Z-s t o p-M e t}$ mice with the nestin-cre transgenics ${ }^{25}$ (nestin-cre;Rosa26 ${ }^{\mathrm{LacZ}-\text { stop-Met }}$, referred to as Nes-R26 ${ }^{M e t}$ ), leading to the excision of the lacZ-floxed cassette and consequently expression of the Met chimeric protein $\left(\mathrm{Met}^{\mathrm{tg}}\right.$ ) in neural tissues (Figures 1c and d). Western blot analysis of E15.5 embryos and P7 mice revealed the presence of Met $^{\text {tg }}$ in dissected brains and spinal cords only after recombination (Figure 1d). To estimate Met ${ }^{\text {tg }}$ levels versus endogenous Met, we performed western blot analysis of brain and spinal cord protein extracts at different developmental stages using antibodies recognizing the kinase domain of both endogenous and $\mathrm{Met}^{\mathrm{tg}}$. Quantification analyses indicated that $\mathrm{Met}^{\mathrm{tg}}$ levels were at least 5/7-fold increased in brains and spinal cords of heterozygous Nes-R26 $6^{M e t}$, when compared with endogenous mouse Met (Figures 1e and f). Consistently, Met $^{\text {tg }}$ levels were twofold higher in homozygous mice compared to heterozygous littermates (Figures 1d-f).

We next characterized the $R 26^{\text {LacZ-stop-Met }}$ mice before and after recombination by following the expression of the lacZ-stop cassette and met $^{\text {tg }}$ transcript in adult brains and spinal cords. We found a decrease in $\beta$-galactosidase activity and lacZ transcripts in Nes-R26 ${ }^{\text {Met }}$ compared with $R 26^{\text {LacZ-- }}$ stop-Met transgenics, indicating that recombination in several brain regions occurred as expected (Figures $2 a-d$, Supplementary Figures 1 and 2). Conversely, met $^{t g}$ was expressed in brains only after recombination in a pattern complementary to lacZ distribution (Figures $2 \mathrm{e}$ and $\mathrm{f}$ ). High levels were found in the hippocampus, cerebellum, cerebral cortex, and cervical spinal cord (Figures 2g-i). Expression studies performed on adult lumbar spinal cord sections revealed also a complementary distribution pattern. In particular, lacZ or $m e t^{t g}$ were found in cells with large nuclei resembling MNs of $R 26^{\mathrm{LacZ}-\text { stop-Met }}$ and Nes-R26 $6^{\mathrm{Met}}$, respectively (Figure 3). Quantification analysis revealed that cre-mediated excision occurred in approximately $56 \%$ of these cells (56.3 \pm 1.1 ; $P<0.0001$; Figure $3 \mathrm{~g}$ ).

Molecular and cellular characterization of Nes-R26 mice. Although the Rosa26 locus drives gene expression ubiquitously, ${ }^{26}$ we observed that the lac $Z$ distribution in brains and spinal cords of adult $R 26^{\text {LacZ-stop-Met }}$ mice appeared restricted to distinct cell types (Figures 2a-d and $3 a-f$, Supplementary Figures 1 and 2). Colocalization studies revealed $\beta$-galactosidase activity predominantly in 
a
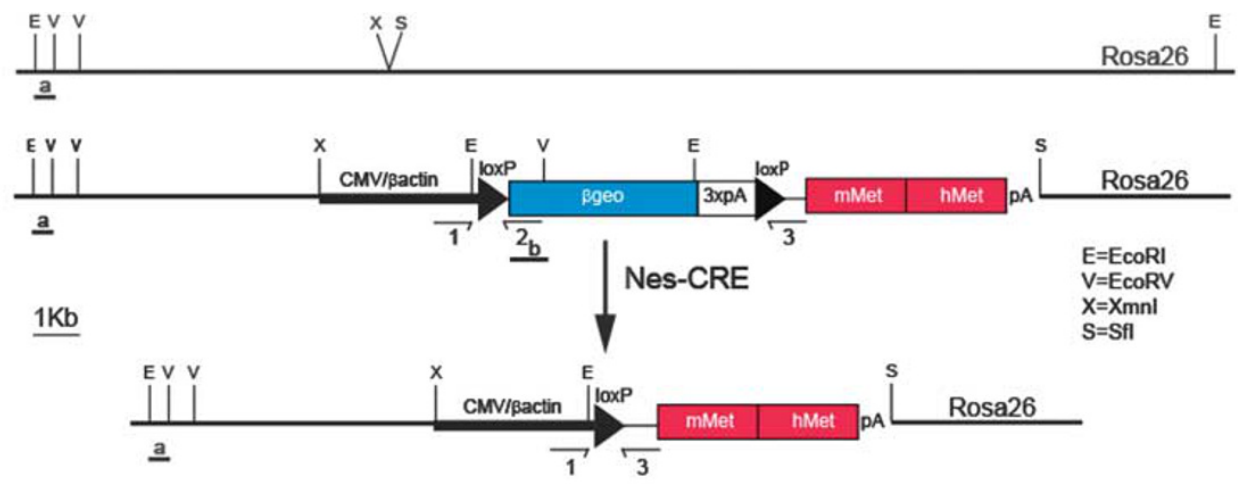

b

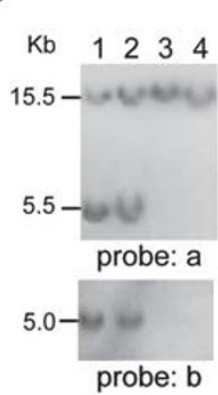

C

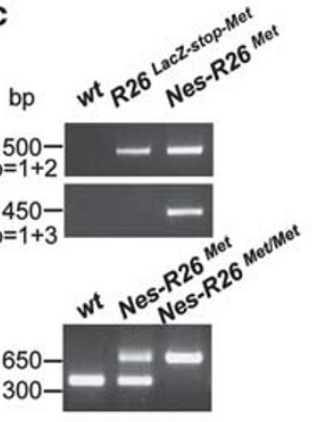

d

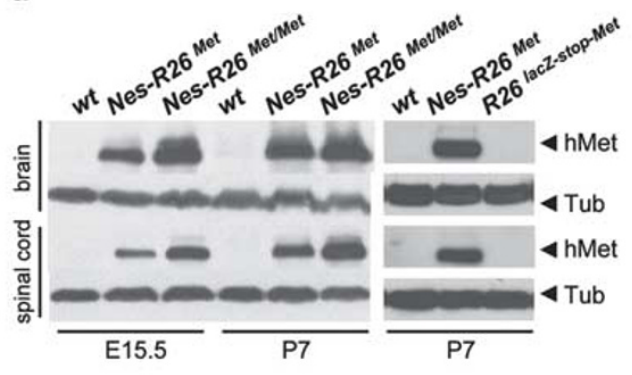

e
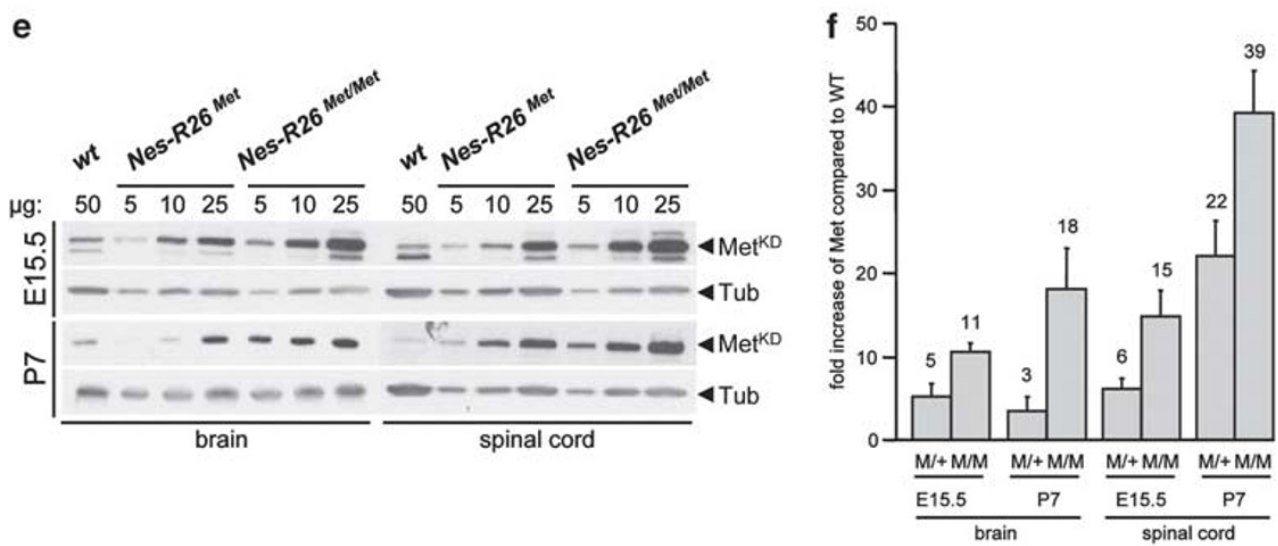

Figure 1 Temporal and tissue-specific Met transgene activation using Cre-mediated recombination. (a) The R26 $6^{\text {Lacz-stop-Met }}$ construct targeted in the Rosa26 locus is shown. The targeting construct consists of the CMV-enhancer and the chicken $\beta$-actin promoter (CMV/ $\beta$-actin) driving the $\beta$-geo reporter and a Met chimeric cDNA. The reporter gene is followed by three copies of the SV40 polyadenylation signal (3xpA) and flanked by loxP sites. The Met chimeric cDNA consists of a $5^{\prime}$ portion encoding the mouse extracellular domain fused to a $3^{\prime}$ region coding for the intracellular human portion. Positions of the probes used for Southern analysis (a and $\mathbf{b}$ ) as well as primers used for PCR $(1,2,3)$ are indicated. (b) Southern blots of neo-resistant ES clones analyzed with probe a (EcoRI digestion; top) and probe b (EcoRV digestion; bottom). The 15.5 Kb band corresponds to the wild-type allele whereas the $5.5 \mathrm{~Kb}$ band depicts the recombinant allele in clones 1 and 2. (c) PCR of mouse-tail genomic DNAs showing the mutant allele before and after Cre recombination (top). The presence of an amplicon in the Nes-R26 $6^{\text {Met }}$ mice with the $1+2$ primers is detected because genotypes are performed using DNA extracted from tails, which include tissues with and without recombination. PCR showing the genotypes of heterozygous and homozygous Nes-R26 ${ }^{\text {Met }}$ mice (bottom). (d) Western blots showing the expression of the Met chimeric protein (using anti-human Met antibodies) in brain and spinal cord extracts from embryos (E15.5) and newborn mice (P7) with the indicated genotypes. (e) Quantification analysis of Met chimeric protein levels versus endogenous Met. Western blot analysis of protein extracts from dissected brains and spinal cords at different developmental stages using antibodies recognizing the Met kinase domain (Met ${ }^{\mathrm{KD}}$ ). (f) Quantification analyses revealed that levels of Met chimeric proteins were at least five- and sevenfolds increased in brains and spinal cords of heterozygous Nes-R26 ${ }^{\text {Met }}$, respectively, when compared with the endogenous mouse Met. Met chimeric levels were double in homozygous mice. Numbers on columns indicate fold of increase in Met protein levels over the endogenous Met. In the graph, Nes-R26 $6^{\text {Met }}$ and Nes-R26 ${ }^{\text {MetMet }}$ genotypes are indicated as $\mathrm{M} /+$ and M/M, respectively. Values are expressed as means \pm S.E.M. Tub, tubulin; hMet, human-Met

NeuN-positive neurons, but not in glial fibrillary acidic protein (GFAP)-positive astrocytes (Figures $4 a-h$ ). The restricted neuronal lacZ expression was also observed in cultured cells (Figures $4 \mathrm{i}-\mathrm{n}$ ). Thus, the genetic setting we adopted (CMVenhancer/ $\beta$-actin-promoter in Rosa26) results in an animal model with a restricted expression of the transgene, indicating that met $^{\text {tg }}$ should be predominantly confined to neurons after nestin-cre-mediated recombination. Consistently, met ${ }^{t g}$ transcripts colocalized with Smi32-positive neurons, but not with GFAP-positive astrocytes (Supplementary Figure 3). The restricted expression of $m e t^{t g}$ in neurons was also observed in Nes-R26 ${ }^{M e t}$ adult spinal cords, 

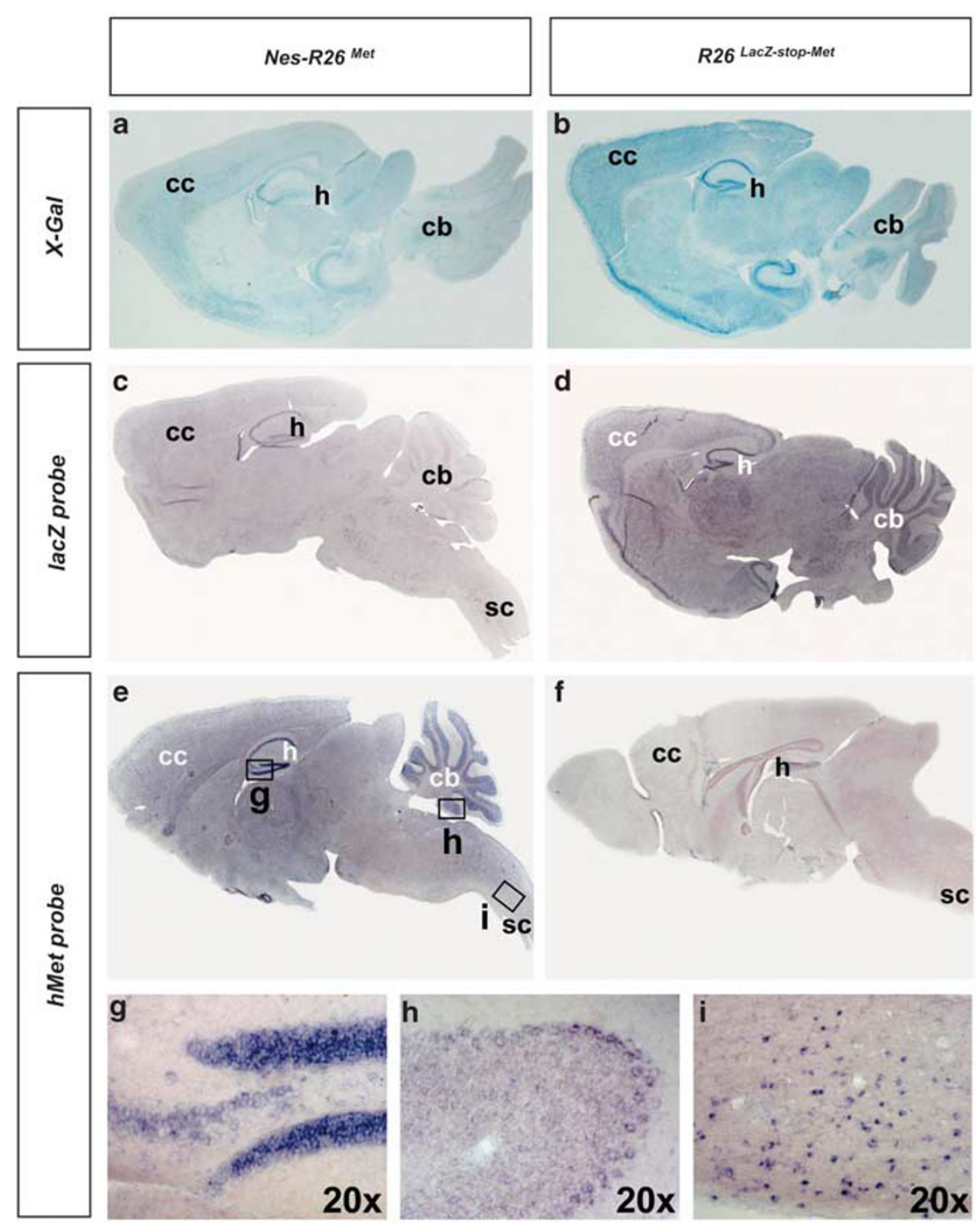

Figure 2 Molecular characterization of Nes-R2 $6^{\text {Met }}$ and $R 26^{L a c Z-s t o p-M e t}$ mice in adult brains. (a-d) Expression of the lacZ reporter gene was followed by measuring $\beta$-galactosidase (X-Gal) activity ( $\mathbf{a}$ and $\mathbf{b}$ ) or its transcript levels ( $\mathbf{c}$ and $\mathbf{d})$ on sagittal sections. Decrease in X-Gal and lacZ transcripts were found after nestin-cre-mediated recombination. (e and $\mathbf{f}$ ) Expression of the met chimeric transgene in sagittal section of adult Nes-R26 $6^{\text {Met }}$ and $R 26^{\text {LacZ-stop-Met }}$ brains. (g-i) High levels of transgenic met transcripts were detected in the hippocampus $(\mathbf{g})$, cerebellum $(\mathbf{h})$, cervical spinal cord (i). Panels $(\mathbf{g}-\mathbf{i})$ show enlarged views of brain areas delineated by the rectangles in $(\mathbf{e})$. cb, cerebellum; cc, cerebral cortex; h, hippocampus; sc, spinal cord

where it was found in dorsal horn neurons, intermediate lateral neurons, and MNs, but not in GFAP-positive astrocytes (Figure 5). Thus, met $t^{t g}$ is predominantly restricted to neurons in Nes-R26 $6^{\mathrm{Met}}$ mice.

We next examined whether Met ${ }^{\text {tg }}$ protein was active by following its phosphorylation state using anti-phospho-Met antibodies. High levels of phosphorylated Met ${ }^{\text {tg }}$ were found in the pons, medulla, lateral ventricles, rostral-migratory stream, olfactory bulbs, cerebral and lumbar spinal cords (Figure 6 and data not shown). These results show that Met ${ }^{\text {tg }}$ is predominantly functional in spatially restricted domains, which possibly correlate to a map of cellular competence for $\mathrm{Met}^{\text {tg }}$ activation influenced by a combination of parameters, such as environmental contexts (e.g., endogenous HGF levels) or permissive intracellular mechanisms (e.g., signalling modulators). Altogether these data show that Nes-R26 ${ }^{M e t}$ mice can be a useful animal model to investigate the functional consequences of enhancing Met levels in distinct cell types, using available tissue-specific cre-lines.

Phenotypical characterization of Nes-R26 ${ }^{\text {Met }}$ mice. As previously discussed, Met regulates specification, axonal growth, and survival of MN subtypes during development. ${ }^{17-20}$ We therefore evaluated whether enhanced Met levels influence MN numbers in Nes-R26 ${ }^{M e t}$ mice. By staining spinal cord sections either with cresyl violet or with vesicularacetylcholie-transporter (VAChT) antibodies, similar MN numbers were found at thoracic (data not shown) or lumbar spinal cord levels in Nes-R26 $6^{\text {Met }}$ and control animals $(P>0.05$; Figures $7 \mathrm{a}-\mathrm{d}$ and $\mathrm{g})$. As expected by the 
colocalization studies, no differences in GFAP-fluorescence intensity were observed ( $P>0.05$; Figures $7 \mathrm{e}, \mathrm{f}$ and $\mathrm{h}$ ).

As body weight is a generic indicator of animal physiology influenced by body metabolism, activity, and feeding behaviour, the weight of Nes-R26 ${ }^{M e t}$ mice was followed over-time and no significant differences were found versus controls $(P>0.05$; Figure $7 \mathrm{j})$. We next performed the rotarod test to
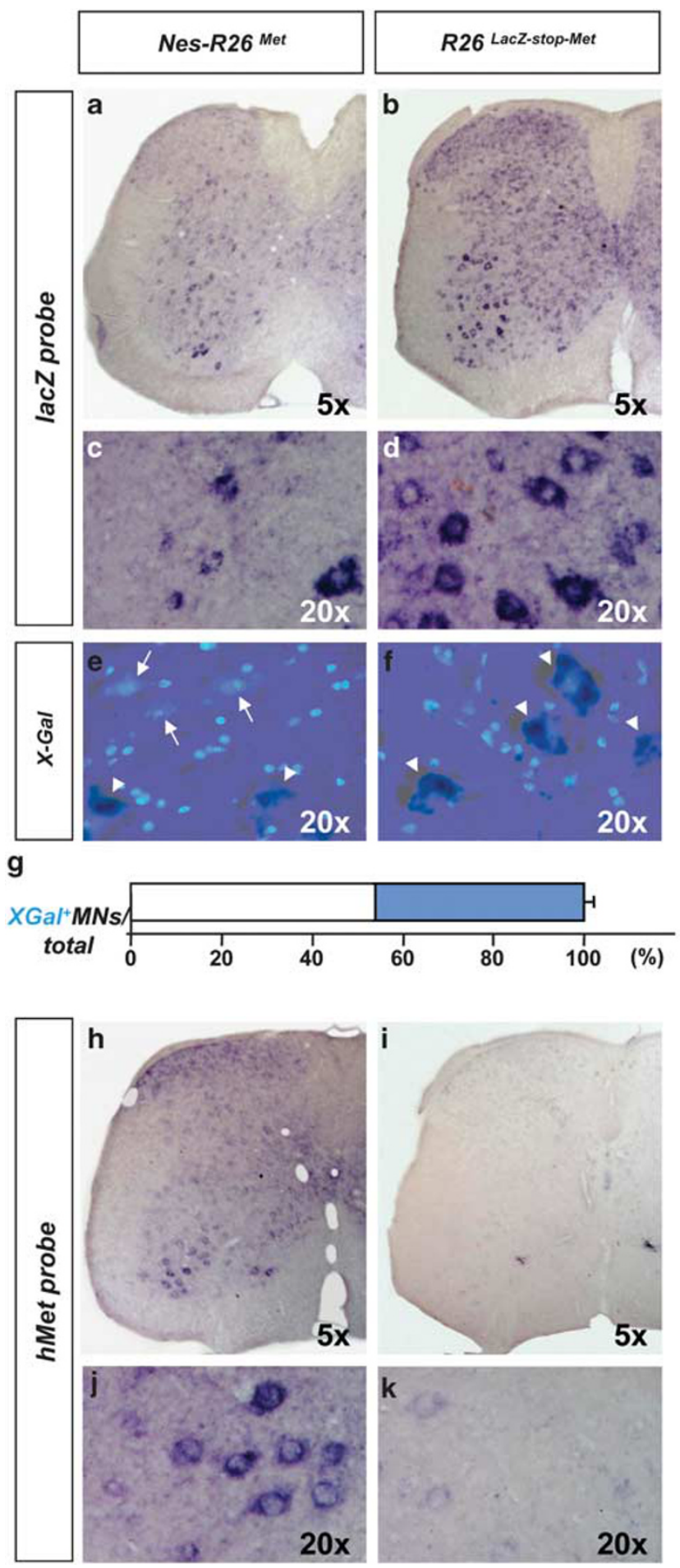

evaluate the overall motor function and no significant differences were found in Nes-R26 $6^{\text {Met }}$ versus controls $(P>0.05$; Figure 7i). Altogether, these studies show that enhancing Met levels in neurons does not cause gross physiological abnormalities.

Neuronal-enhanced Met levels counteract ALS symptoms in SOD transgenic mice. We next investigated the functional relevance of genetically enhancing Met signalling levels in the context of a neurodegenerative disorder, such as the ALS. The Nes-R26 $6^{\text {Met }}$ mice were therefore crossed with a strain carrying high copy numbers of the $S O D 1^{G 93 A}$ transgene to generate an ALS animal model with increased Met levels in neurons. Five groups of mice were generated: (a) wild-type;

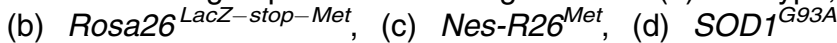
(referred to as $S O D$ ), and (e) Nes-R26 ${ }^{\text {Met }}$;SOD $1^{\text {G93A }}$ (referred to as Nes-R26 $6^{M e t}-S O D$ ). As no significant changes were observed between wild-type, Rosa26 $6^{\text {LacZ-stop-Met, and Nes-R26 }} 6^{\text {Met }}$ for all parameters examined, results of control animals included these three groups.

By evaluating the life span of $S O D$ and Nes-R26 ${ }^{M e t}-S O D$ mice, we found that neuronal-enhanced Met levels prolonged the survival by 13 days (mean age, SOD: $136 \pm 2$ days; Nes-R26 ${ }^{\text {Met }}-S O D$ : $149 \pm 3$ days; $P=0.0021$; Figure $8 \mathrm{a}$ ). As reduction of body weight is an objective measure of ALS disease, we examined its evolution in SOD and Nes-R26 $6^{M e t}$. $S O D$ mice, and found that neuronal-enhanced Met levels delayed body weight loss. In particular, loss of $10 \%$ body weight was retarded for 13 days (SOD: $123 \pm 3$ days; Nes$R 26^{\text {Met }}-S O D$ : $136 \pm 5$ days; $P=0.0094$; Figure $8 \mathrm{~b}$ ), whereas no significant differences were observed during disease progression (SOD: $12.9 \pm 2.5$ days; Nes-R26 ${ }^{\text {Met }}-S O D$ : $13 \pm 2.4$ days; $P>0.05$; Figure $8 \mathrm{c}$ ). Together, these results indicate that enhanced Met levels in neurons counteract ALS symptoms in SOD transgenic mice.

Improved motor performance and delayed onset of paralysis in SOD mice with neuronal-enhanced Met levels. The neuro-degeneration defects causing ALS disease lead to progressive muscle weakness, atrophy, and paralysis. Screwed hindlimbs and locomotor defects are among the first symptoms affecting transgenic ALS mice. We

Figure 3 Molecular analysis of Nes-R26 $6^{\text {Met }}$ and $R 26^{L a c Z-\text { stop-Met }}$ mice in adult lumbar spinal cords on transversal sections. (a and $\mathbf{b})$ In situ hybridization using lacZ riboprobes. (c and d) Enlarged view of the ventral regions, showing lacZ expression in distinct cell types characterized by large cell nuclei resembling MNs in $R 26^{\text {LacZ-stop-Met }}$ and a decrease in its levels after nestin-cre-mediated recombination in Nes-R26 ${ }^{\text {Met }}$. (e and $\mathbf{f}$ ) Section showing the overlap of X-Gal activity and DAPI staining in lumbar spinal cords. X-Gal-negative cells with large nuclei were predominantly found in Nes-R2 $6^{\text {Met }}$, but not in R2 $6^{\text {LacZ-stop-Met }}$ transgenics. Arrows and arrowheads points to X-Gal-negative and X-Gal-positive cells with large nuclei, respectively. (g) Quantification analysis of X-Gal-positive (blue) and X-Gal-negative cells with large nuclei (resembling MNs; white) in Nes-R26 ${ }^{\text {Met }}$ mice, showing that nestin-cre-mediated lacZ excision occurred in approximately $56 \%$ of these cells. Values are expressed as means \pm S.E.M. ( $\mathbf{h}-\mathbf{k})$ Expression of the met chimeric transgene in lumbar spinal cords. Panels ( $\mathbf{j}$ and $\mathbf{k}$ ) show an enlarged view of ventral spinal cords and met transgenic expression in cells resembling MNs 


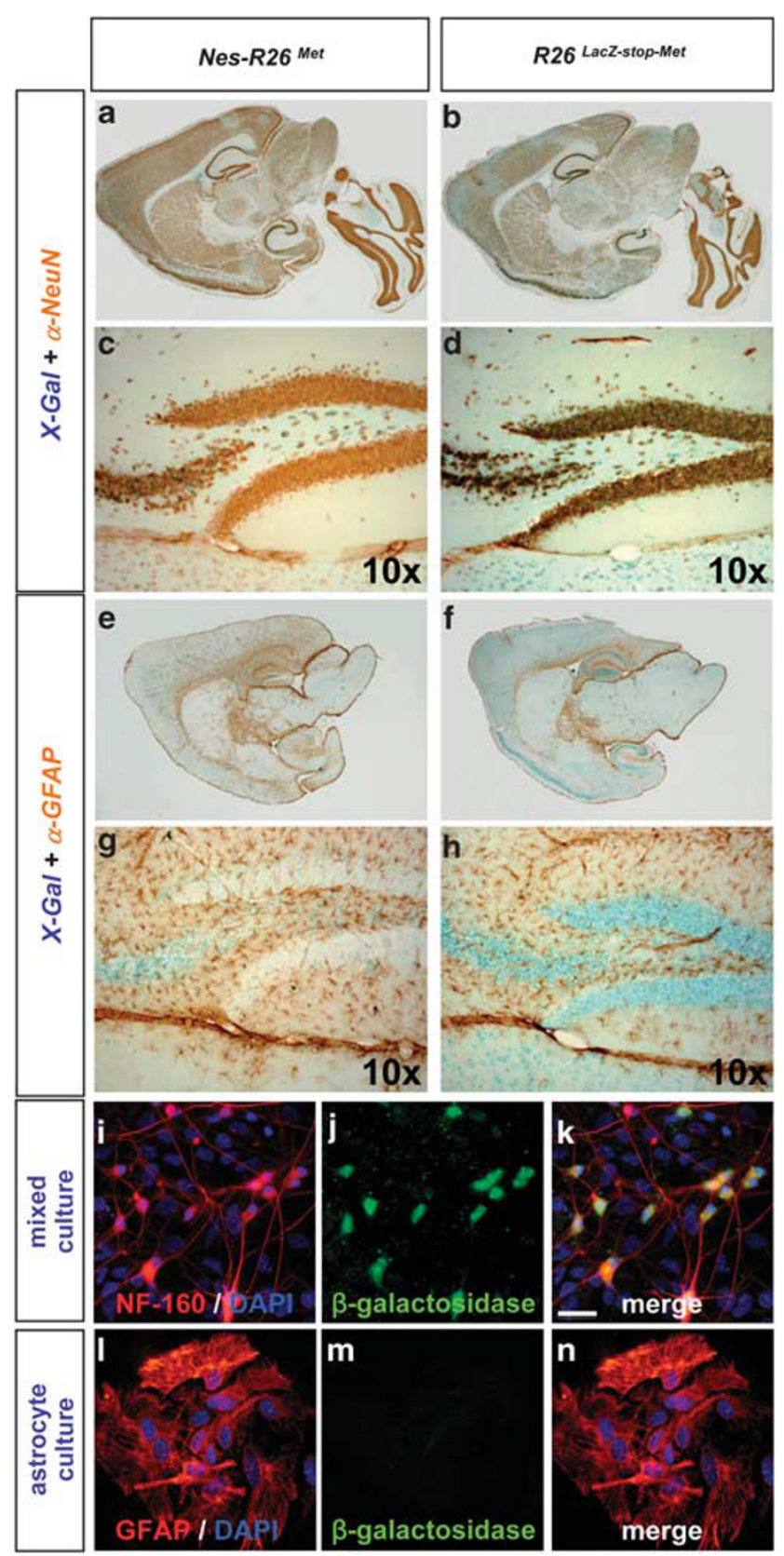

Figure 4 Subcellular localization of the lacZ reporter gene in Nes-R26 $6^{\text {Met }}$ and $R 26^{\text {LacZ-stop-Met }}$ mice. (a and $\mathbf{b}$ ) Colocalization studies of X-Gal activity with NeuN protein showing the reporter activity in neuronal cell types. (c and $\mathbf{d}$ ) Enlarged view of the hippocampus area. (e-h) Colocalization studies of X-Gal activity with GFAP protein showing that the lacZ reporter gene is not predominantly expressed in astrocytes. Panels ( $\mathbf{g}$ and $\mathbf{h}$ ) correspond to an enlarged view of the hippocampus. (i-k) Mixed cell cultures derived from E12.5 R26 LacZ-stop-Met spinal cords were immunostained for neurofilament-160 (red) and $\beta$-galactosidase (green) proteins. (i-n) Astrocyte cultures from P2 R26 $6^{\text {LacZ-stop-Met }}$ spinal cords immunostained for GFAP (red) and $\beta$-galactosidase (green). DAPI was used to counterstain nuclei (blue), scale bar: $20 \mu \mathrm{m}$

monitored the appearance and progression of motor defects in $S O D$ versus Nes-R26 ${ }^{M e t}$-SOD compared with controls by employing swimming tank and footprint assays. ${ }^{27}$ Onset of swimming defects was delayed by 14 days, as estimated by

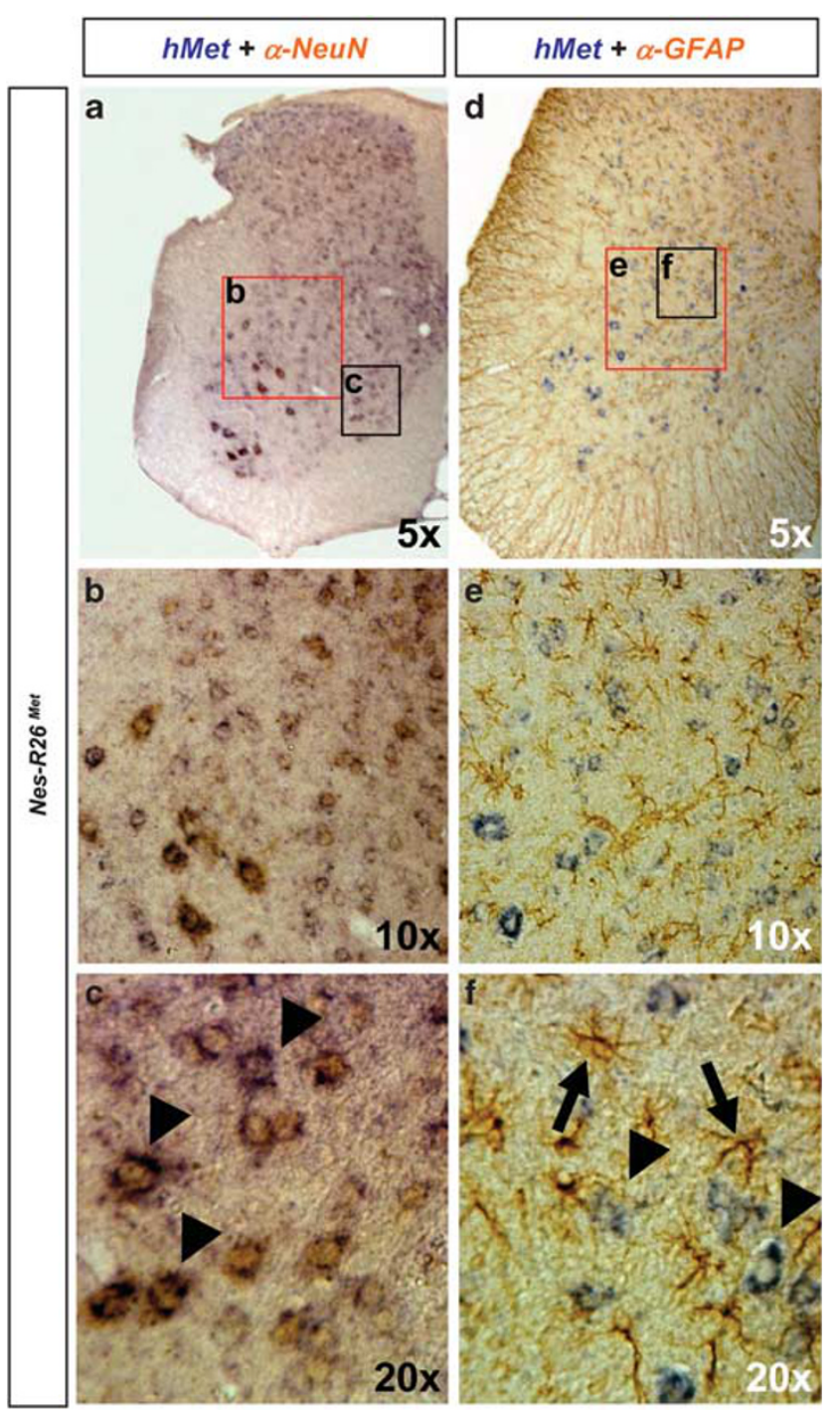

Figure 5 Subcellular localization of chimeric met transcripts in lumbar spinal cords of adult Nes-R26 ${ }^{\text {Met }}$ mice. (a-c) Colocalization studies of exogenous met transcript with NeuN protein showing met expression in neuronal cell types. (d-f) Colocalization studies of exogenous met transcript with GFAP protein showing that transgenic met is not predominantly expressed in astrocytes. Panels ( $\mathbf{b}$ and $\mathbf{e})$, panels ( $\mathbf{c}$ and $\mathbf{f}$ ) correspond to an enlarged view of spinal cord areas indicated by red and black rectangles in (a and $\mathbf{b}$ ), respectively. Arrowheads in (c) point to MNs co-expressing chimeric met transcript and NeuN protein. Arrows and arrowheads in (f) indicate GFAP-positive astrocytes and MN expressing chimeric met transcripts, respectively

the increased time that mice needed to execute this motor task (SOD: $113 \pm 3$ days; Nes-R26 ${ }^{\text {Met }}-S O D$ : $127 \pm 3$ days; $P=0.0015$; Figure $8 \mathrm{~d}$ ), whereas disease progression was unchanged (SOD: $30 \pm 3.9$ days; Nes-R26 $6^{\text {Met }}-S O D: 22 \pm 2.7$ days; $P>0.05$; Figure $8 \mathrm{e}$ ). Therefore, neuronal-enhanced Met improved motor strength and swimming performance of $S O D$ mice by acting specifically on disease onset.

The motor capability of Nes-R26 $6^{\text {Met }}-S O D$ versus SOD mice was further evaluated by performing footprint studies (Supplementary Figure 4). The forepaw/hindpaw overlap analysis revealed a delay of 19 days in the locomotor gait dysfunction (SOD: $108 \pm 3$ days; Nes-R26 ${ }^{\text {Met }}-S O D$ : $127 \pm 3$ days; 


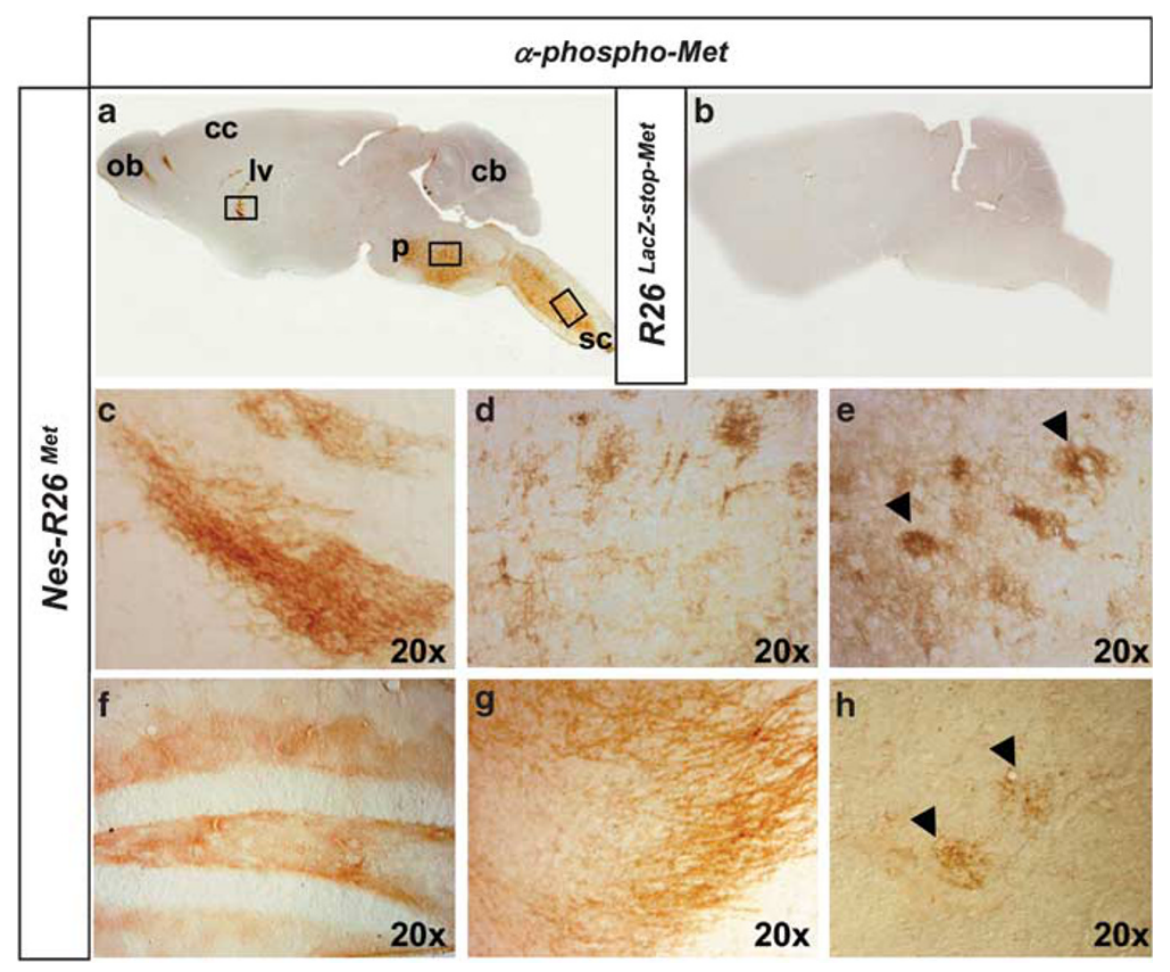

Figure 6 Tissue-distribution of activated chimeric Met in adult brains and spinal cords. (a and $\mathbf{b}$ ) Sagittal sections of adult brains showing phospho-Met staining in Nes-R26 $6^{\text {Met }}$, but not in R26 $6^{\text {LacZ-stop-Met }}$ mice. (c-h) Enlarged view of phospho-Met distribution in the lateral ventricle (c), pons (d), cervical spinal cord (e), corresponding to regions indicated by squares in panel (a). Distribution of phospho-Met in the hippocampus (f), olfactory bulb (g), and lumbar spinal cord (h). Arrowheads in (e and $\mathbf{h}$ ) point to phospho-Met-positive cells with large nuclei resembling MNs. cb, cerebellum; cc, cerebral cortex; Iv, lateral ventricle; ob, olfactory bulb; p, pons; sc, spinal cord

$P=0.0009$; Figure 8f), accompanied by a delay of 9 days in the appearance of step-length defects (SOD: $106 \pm 2$ days; Nes-R26 ${ }^{\text {Met }}$-SOD: $115 \pm 2$ days; $P=0.0136$; Figure $8 \mathrm{~h}$ ). The motor performance decline rate was not appreciably different between SOD and Nes-R26 ${ }^{M e t}$-SOD mice, showing that when the disease has started, it progresses at the same rate (overlap, SOD: $30 \pm 3.9$ days; Nes-R26 ${ }^{M e t}-S O D$ : $22 \pm 22.7$ days; $P>0.05$; step-length, SOD: $32 \pm 3.1$ days; Nes-R26 ${ }^{\text {Met }}$ SOD: $34 \pm 1.7$ days; $P>0.05$; Figures $8 \mathrm{~g}$ and $\mathrm{i}$ ).

Neuronal-enhanced Met levels attenuate MN loss in spinal cords of SOD mice. As motor performances were transiently improved in Nes-R26 $6^{M e t}-S O D$ mice by delaying disease onset, we evaluated the neuroprotective effects of increased Met levels by quantifying lumbar spinal cord MNs. For these studies, we selected three animals among the Nes-R26 ${ }^{\text {Met }}-S O D, S O D$, and controls at the symptomatic disease phase (120 days). This stage was chosen because all behavioural studies showed significant differences between groups. Lumbar spinal cord sections were stained with VAChT antibodies and MN numbers were determined (Figures $9 \mathrm{a}-\mathrm{c}$ and $\mathrm{m}$ ). As expected, we observed a significant $60 \% \mathrm{MN}$ loss in SOD mice compared with controls $(P=0.0065)$. By contrast, neuronal-enhanced Met in Nes-R26 $6^{M e t}-S O D$ mice led to an improvement of $\mathrm{MN}$ maintenance as the surviving $\mathrm{MN}$ numbers increased by $32 \%$ compared with $S O D(P=0.0002$; Figure $9 \mathrm{~m})$.

We next assessed to what extent enhancing Met function in neurons influenced astrogliosis and microglia activation, which appear at disease onset and become more prominent during progression. $^{9}$ In contrast to controls, activated GFAP-positive astrocytes (changes in fluorescence intensity) were detected in lumbar spinal cords, although reduced in Nes-R26 ${ }^{\text {Met }}$-SOD compared with SOD (SOD: $15.5 \pm$ $1.9 \times 10^{8} ; \quad$ Nes-R26 ${ }^{\text {Met }}$-SOD: $\quad 9.9 \pm 1.4 \times 10^{8} ; \quad P=0.0164$; Figures $9 d-f$ and $n)$. Similarly, the number of microglial cells was reduced in Nes-R26 $6^{M e t}-S O D$ mice compared with SOD (SOD: $\quad 281.7 \pm 14.6 ; \quad$ Nes-R26 ${ }^{\text {Met }}-S O D: \quad 222.1 \pm 15.5$; $P=0.0016$; Figures $9 \mathrm{~g}-\mathrm{i}$ and $\mathrm{o}$ ). Analysis of muscle innervation revealed that the increased MN numbers in Nes-R26 ${ }^{M e t}$ $S O D$ was accompanied by an enhanced integrity of neuromuscular junctions (NMJs; SOD: $16 \pm 1.8 \%$; Nes-R26 $6^{\mathrm{Met}}$ SOD: $41.7 \pm 11.4 \% ; \quad P=0.041$; controls: $84.4 \pm 7.9 \%$; Figure 9p). Thus, increased neuronal Met levels elicit a combination of protective effects in different cell types: (1) cellautonomous protective effects on spinal cord MNs and for NMJ maintenance; (2) non-cell-autonomous delay of astrocyte activation and increased microglia cell numbers.

\section{Discussion}

Most of neurodegenerative diseases result from a combinatorial action of pathological signals produced by neurons themselves and by neighbouring cells acting in a non-cellautonomous manner. ${ }^{7} \mathrm{~A}$ number of molecules including trophic factors and their receptors can elicit beneficial effects on disease-related cells when applied in vitro and/or when delivered in disease animal models. Understanding how these 

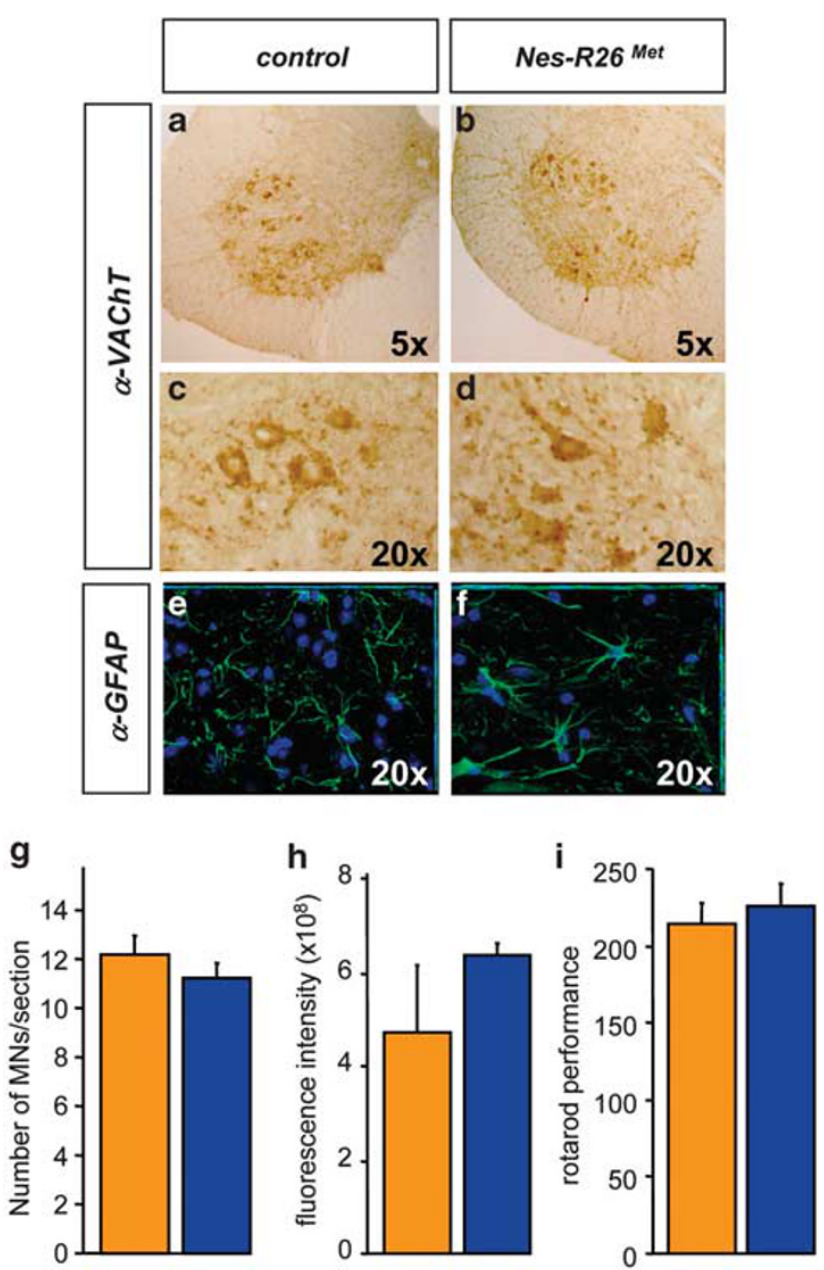

control

Nes-R26 Met

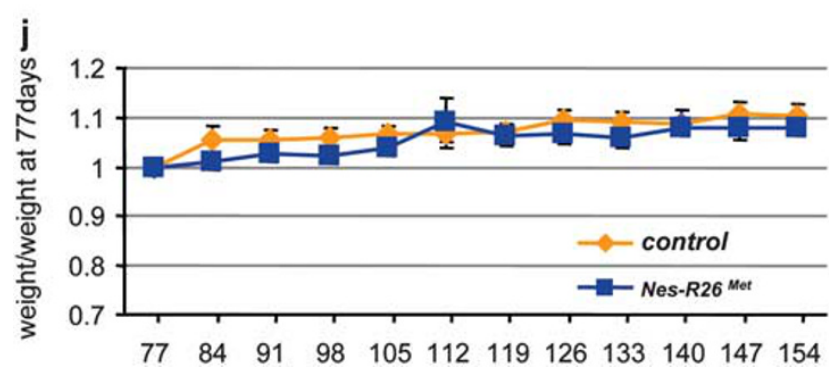

Figure 7 Molecular and functional characterization of Nes-R2 $6^{\text {Met }}$ mice versus controls. (a-f) Transversal sections through lumbar spinal cords showing similar numbers of VAChT-positive (a-d) and GFAP-positive (e and $\mathbf{f}$ ) cells. ( $\mathbf{g}$ and $\mathbf{h}$ ) Quantification studies showed no significant difference in numbers of VAChTimmunopositive cells $(\mathbf{g} ; P>0.05)$ and GFAP-fluorescence intensity $(\mathrm{h} ; P>0.05)$ among the two groups of mice $(n=3)$. (i) Rotarod behavioural analysis in Nes-R2 ${ }^{\text {Met }}$ and control littermate mice showing that enhanced neuronal Met levels did not significantly influence locomotor performance $(P>0.05 ; n=10)$. (j) Body weight analysis in Nes-Metg and control mice showed no significant differences overtime. Body weight is expressed as weight evolution compared with that of mice at age 77 days. Values are expressed as means \pm S.E.M.

molecules act on dysfunctional cells remains a key topic to clarify disease mechanisms and to evaluate their use for therapies. We show here that enhanced signalling by Met has an impact on a specific stage of ALS pathology when it is selectively upregulated in neurons. Indeed, transgenemediated neuronal expression of Met elicits a beneficial effect in $S O D 1^{G 93 A}$ by delaying disease onset, but not progression.

Our results are based on a genetic approach involving the generation of conditional met $t^{t g}$ mice, in which Met signalling levels is modulated in a temporally and spatially regulated manner. Such an approach offers the possibility of exploring how enhanced Met signalling above endogenous levels influences cell fate in developmental events, in adult physiology, and in pathological conditions. Loss of Met function during development interferes with identity acquisition, axonal growth, and survival of MN subsets. ${ }^{2,17-20} \mathrm{We}$ show here that neuronal-enhanced Met signalling levels do not affect either MN development or function in adulthood, whereas it influences MN maintenance in ALS pathological conditions. Thus, it is likely that excessive Met functions are restrained by mechanisms such as tissue homeostasis or by limiting amounts of ligand. Importantly, the dispensable function of Met in several adult tissues is in contrast to its requirement in counteracting degenerative processes following injuries, such as axotomy, ${ }^{21,22}$ hepatectomy, ${ }^{28}$ and skinwound. ${ }^{29}$ These regenerative studies together with our findings indicate that in a pathological context, cell types like neurons become sensitive to the beneficial effects provided by Met. The generation of compound transgenics by crossing the $R 26^{\text {LacZ-stop-Met }}$ mice with available cre-lines will offer a unique genetic setting for determining tissue-specific sensitiveness to enhanced Met signalling either during development, in adulthood, or in pathologies.

The pleiotropic functions elicited by the HGF/Met system in neurons have boosted the interest in exploring its potential for

Figure 8 Neuronal-enhanced Met signalling levels in ALS mice improves survival and locomotor performance by delaying disease onset. (a) Survival analysis of Nes-R26 $6^{\text {Met }}$-SOD (red) and SOD (green) mice $(n=40)$ showing a delay of 13 days of average life span. (b) The loss of $10 \%$ body weight was 13 day delayed in Nes-R26 $6^{\text {Met }}$. $S O D(n=11)$ compared with SOD $(n=17)$ mice. (c) Body weight loss was not significantly different in Nes-R26 ${ }^{\text {Met }}$-SOD compared with SOD mice once the disease started $(P>0.05)$. (d and e) Motor performance analysis using a 1 meter swimming tank device. Panel (d) shows a delay of 14 days in motor defect onset of Nes-R26 ${ }^{\text {Met }}-S O D$ mice $(n=11)$ compared with $S O D$ transgenics $(n=17)$. Panel (e) shows the analysis of the duration of locomotor defects with not significant differences between groups $(P>0.05)$. (f-i) Comparison of motor performance using the footprint test. Analysis of the forepaw/hindpaw overlap revealed a 19 day improvement in Nes-R26 ${ }^{\text {Met-SOD mice }}$ $(n=11)$ compared with $S O D$ transgenics $(n=17 ; f)$. No significant differences were found during disease progression $(\mathbf{g} ; P>0.05)$. Step length defects also appeared with a delay of 9 days in Nes-R26 $6^{\text {Met }}-S O D$ compared with $S O D$ mice $(\mathbf{h})$. Again, no changes were found during disease progression (i; $\left.P>0.05\right)$. $\mathbf{a}, \mathbf{b}, \mathbf{d}, \mathbf{f}$ and $\mathbf{h}$ are Kaplan-Meier curves. Values are expressed as means \pm S.E.M. 
a

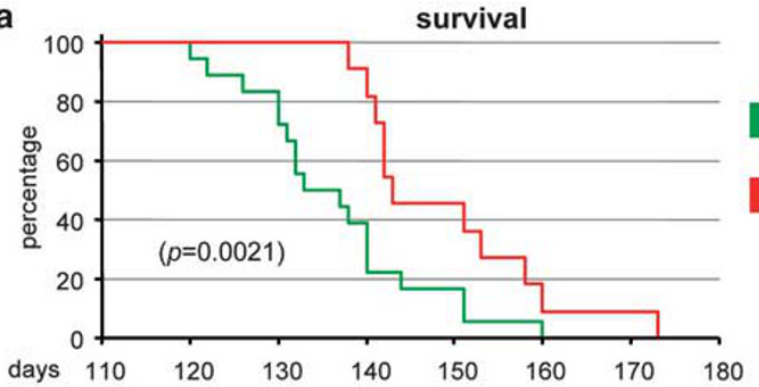

$S O D$

Nes-R26 ${ }^{\text {Met_SOD }}$

b

loss of $10 \%$ weight

C
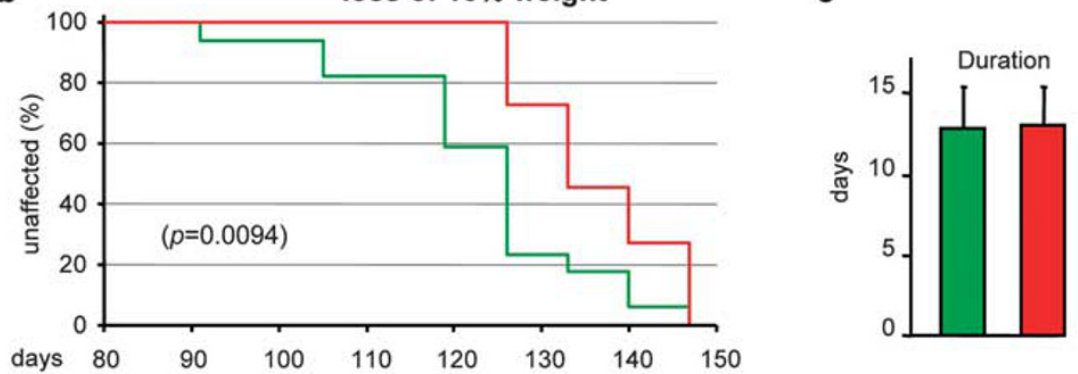

d

swimming

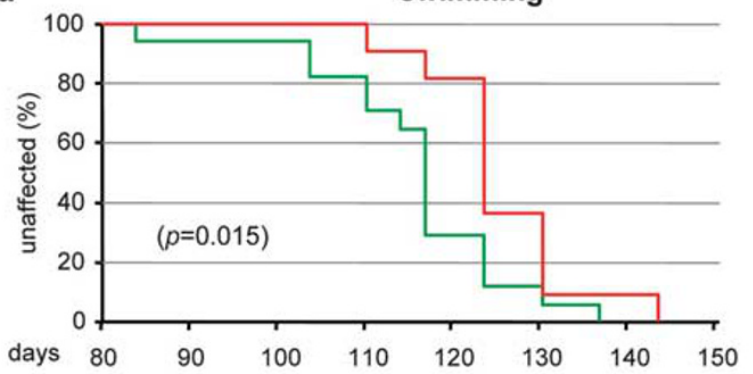

e

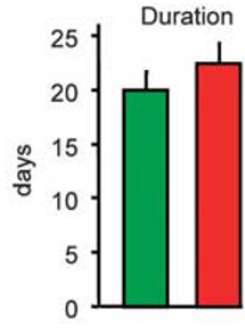

f

overlap

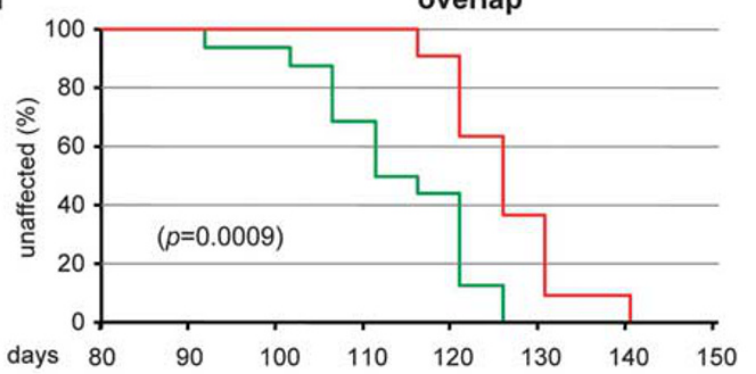

g

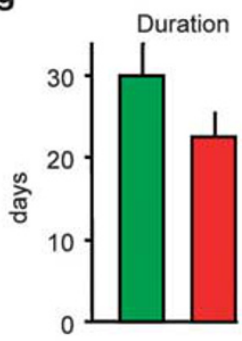

h

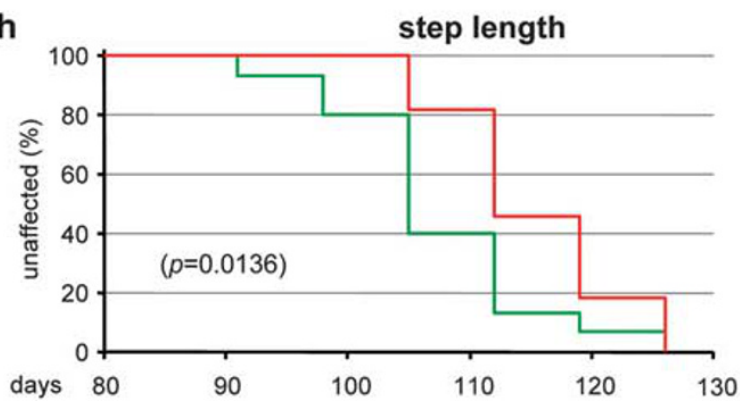

i

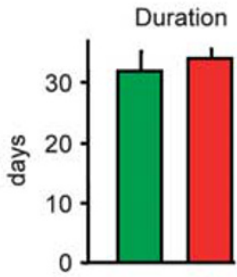



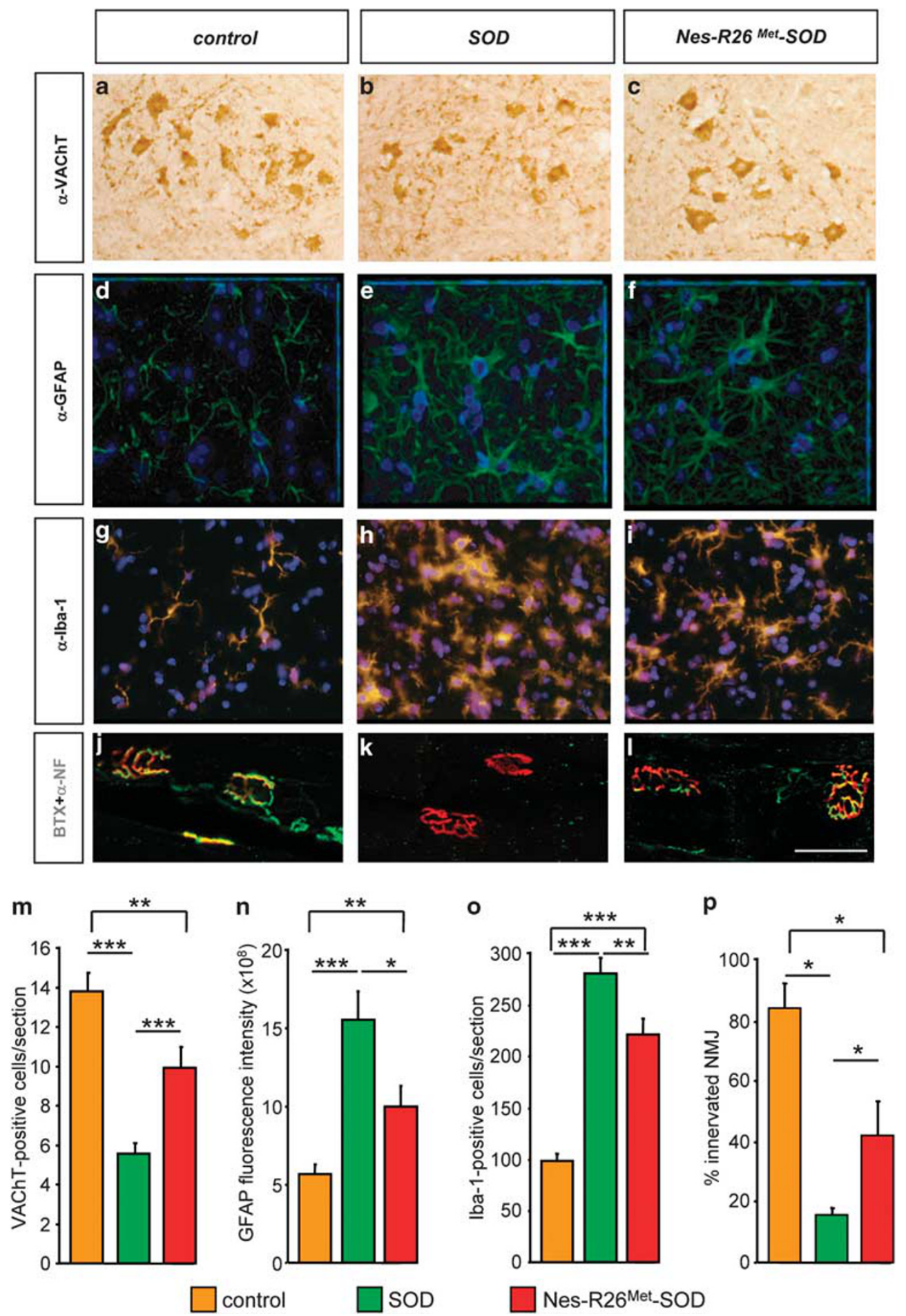

Figure 9 Effects of enhanced Met signalling in MN maintenance and astrogliosis at ALS symptomatic phase (120 days). (a-c) VAChT-stained sections through the ventral horn of the lumbar spinal cord showed an increase in MN maintenance in Nes-R26 ${ }^{\text {Met }}$-SOD compared with SOD transgenics. (d-f) GFAP-stained sections through the ventral horn of the lumbar spinal cords showing astrogliosis in Nes-R26 $6^{\text {Met }}$-SOD and SOD mice. (g-i) lba-1-stained sections through the ventral horn of the lumbar spinal cords showing an increase in the number of microglial cells in Nes-R26 $6^{\text {Met }}-S O D$ and $S O D$ mice. (j-I) Immunofluorescence staining of gastrocnemius muscle with $\alpha$-bungarotoxin-tetramethylrhodamine (red), antineurofilament (green). Scale bar $50 \mu \mathrm{m}$. (m) Quantification of MN numbers (VAChT-positive) among the three groups of mice, showing a $32 \%$ increase in Nes-R26 ${ }^{\text {Met }}$-SOD compared with SOD mice (Nes-R26 ${ }^{\text {Met }}$-SOD versus SOD: $P=0.0002$; SOD versus control: $P<0.0001$; Nes-R26 ${ }^{\text {Met }}$-SOD versus control: $P=0.006 ; n=3$ ). (n) Quantification of fluorescence intensity of GFAP-immunopositive cells. Significant differences were observed between the three groups (Nes-R26 $6^{\text {Met }}-S O D$ versus SOD: $P=0.0164$; $S O D$ versus control: $P=0.0002$; Nes-R26 ${ }^{\text {Met }}$-SOD versus control: $P=0.0084 ; n=3$ ). (o) Quantification of lba-1-positive cells. Significant differences in microglia numbers were observed between the three groups (Nes-R26 ${ }^{\text {Met }}$-SOD versus SOD: $P=0.0016$; SOD versus control and Nes-R26 ${ }^{\text {Met }}$-SOD versus control: $P<0.0001 ; n=3$ ). (p) The percentage of $\alpha$-Bungarotoxinstained end-plates showing complete or partial colocalization with neurofilament staining was evaluated in the three groups (Nes-R26 ${ }^{\text {Met }}-S O D$ versus SOD: $P=0.0416$; controls versus SOD: $P=0.0143$; controls versus Nes-R26 ${ }^{\text {Met }}-S O D: P=0.0256$ ). Values are expressed as means \pm S.E.M. ${ }^{\star \star \star \star} P<0.001,{ }^{\star \star} P<0.01,{ }^{\star} P<0.05$ 
ALS therapy through several strategies. HGF intrathecal administration at disease onset provided evidence that, when present at high doses and accessible to different disease cells, HGF/Met attenuates MN degeneration and retards disease progression by 11 days. ${ }^{30}$ However, these studies did not clarify whether, and to what extent, the HGF/Met system exerts support on MNs in a cell-autonomous manner. Insights to this issue come from studies based on genetic neuronal delivery of HGF in the low copy number $S O D 1^{G 93 A}$ mice. In particular, hgf expression driven by the neuron-specific enolase-promoter delayed disease onset by approximately 28 days, rather than influencing its progression. ${ }^{23}$ However, as exogenous HGF is expressed and secreted by neurons, these hgf transgenic mice did not allow discriminating between the HGF effects on MNs versus those elicited on astrocytes, which in turn influence MNs and microglia function. Consistently, a decrease in the number of microglia, reactive astrocytes, and $\mathrm{MN}$ loss was observed in hgf transgenics. Our mouse model allowed discrimination between the cell-autonomous effects elicited by enhanced Met signalling in MNs and those influenced by HGF on other dysfunctional cells. Moreover, the Nes-R26 ${ }^{\text {Met }}$ mice established that Met signalling in MNs selectively counteracts ALS disease onset. It remains to be investigated what contribution enhanced Met signalling, above endogenous levels in astrocytes and microglia, could have with respect to disease evolution.

The severity of ALS and the lack of effective therapeutic strategies are driving efforts to explore agents, applied either separately or in combination, to counteract disease symptoms. Concerning trophic factors, HGF could offer therapeutic advantages at multiple levels. It is noteworthy that endogenous Met is upregulated starting from ALS onset in ventral spinal cords of $S O D 1^{G 93 A}$ mice (data not shown and see Sun et al. ${ }^{23}$ ). These observations indicate that endogenous Met is turned on to counteract ALS symptoms, but endogenous HGF levels may not be sufficient to reverse the damage, as was found studying regeneration after optic-nerve axotomy (unpublished results). Moreover, as HGF/Met elicits functions in muscle cells, ${ }^{31,32}$ it is possible that ectopic HGF in muscles would also counteract neuro-muscular-junction denervation and muscle atrophy. Indeed, HGF favours the formation of NMJs during development. ${ }^{33}$ Although enhanced Met activation is often associated with tumour formation and metastasis, we did not observe side effects such as neoplasia in Nes-R26 $6^{\mathrm{Met}}$ mice despite $\mathrm{Met}^{\mathrm{tg}}$ expression levels in regions of the nervous system. Thus, the beneficial effects of HGF/ Met on ALS degenerative processes appear to be well tolerated in healthy nervous system tissues.

The use of the conditional ALS mouse model, in which the mutant SOD1 gene can be deleted according to the cre-transgenic line used, has been instrumental in clarifying the influence of distinct cell types during ALS evolution. In particular, selective reduction of mutant SOD1 in MNs predominantly impacts on disease onset and its early phase. In contrast, reduced mutant SOD1 either in astrocytes or in microglia mainly influences the late stage of disease progression. ${ }^{8,9}$ Thus, although recombination in Nes- $R 26^{M e t}$ mice did not occur in $44 \%$ of lumbar spinal cord MNs, rebalancing the levels of stress and survival signals and/or protecting presynaptic terminals in ALS MNs, either by providing RTK support (our studies), or by removing signals such as BAX influencing NMJ integrity, ${ }^{12}$ or by depleting mutant SOD, 8,9 ameliorates ALS by selectively delaying disease onset. It is known that the initial MN damage is followed by a progressive increase in cytotoxic and inflammatory mediator levels, which further affect MN themselves and neighbouring cells. Astrocytes and microglia are the predominant cell types driving disease progression towards death. Although disease progression is unchanged in Nes-R26 $6^{M e t}$ mice, our genetic analysis show that enhanced-neuronal Met in SOD mice impacts on distinct cell types involved in the ALS disease: MNs, in a cell-autonomous manner, possibly by providing trophic support and/or maintenance of NMJ integrity and astrocytes and microglia, in a non-cell-autonomous manner, by delaying their activation. Future studies will establish the relative contribution of each individual event in delaying the onset of the disease by neuronal Met signalling and uncover the underlying mechanisms.

Understanding how therapeutic reagents act at cellular levels is needed to accelerate the progress of promising treatments towards the clinic. Our findings emphasize the relevance of genetically assessing the effects of agents on distinct cell types implicated in a disease and during its evolution. Although successful therapies for ALS will possibly require concomitant actions on distinct dysfunctional cells, our results highlight the considerable therapeutic potential of modulating RTK signalling in MNs to combat degenerative signals.

\section{Materials and Methods}

Generation of $\mathbf{R} 26^{\text {LacZ-stop-Met }}$ mice. The $R 26^{\text {LacZ-stop-Met }}$ mice were generated by taking advantage of the loxP-flanked ('floxed')-stop cassette system. To generate the chimeric mouse-human gene, the human Met cDNA encoding the transmembrane and cytoplasmic portion was fused in-frame with the mouse extracellular cDNA sequence using the Pvull site present in both sequences. We chose such a strategy to ensure that the Met chimeric protein interacts efficiently with the endogenous mouse HGF, but can still be identified from the endogenous mouse Met protein. The fusion product was subsequently subcloned into the pCALL2 vector downstream of the insert containing the CMV enhancer-chicken $\beta$-actin promoter followed by the loxP-flanked $\beta$-geo/3xpA cassette. This vector is referred to as pCALL-Met. To generate the Rosa26 targeting construct, the insert containing the CMV-enhancer/chicken- $\beta$-actin-promoter-loxP-flanked $\beta$-geo/3xpAMet was subcloned into the Xhol site of pRosa- 1 vector previously modified using a poly-linker. The targeting vector was electroporated into R1 ES cell lines. Cell culture, electroporation, selection, and Southern blot analyses were performed as previously described..$^{32}$ To identify recombined clones, genomic DNA was digested with $E c O R I$ or $E c o R V$ and probed with an external or internal probe, respectively. Two selected ES cell lines carrying the homologous recombination were used to generate the $R 26^{\text {LacZ-stop-Met }}$ mice through blastocyst injections.

Transgenic mice. The mouse line expressing cre recombinase under the nestin promoter was previously described. ${ }^{25}$ The B6SJL-Tg(SOD1*G93A) 1 Gur(SOD1 $1^{\mathrm{G} 93 \mathrm{~A}}$ (SOD1 ${ }^{\mathrm{G} 93 \mathrm{~A}}$ ) mouse line was used as ALS disease model. ${ }^{34}$ Both R26 LacZ-stop-Met and nestin-cre mice were backcrossed into the B6SJL genetic background before breeding with the $\mathrm{SOD} 1^{\mathrm{G} 93 \mathrm{~A}}$ transgenics. The number of mice used for behavioural and immuno-histochemical studies are indicated in figure legends. Each genetic group consisted of a mixed population of equal numbers of males and females. The presence of a vaginal plug in the morning was considered as 0.5 embryonic day (E0.5). All procedures involving the use of animals were performed in accordance with the European Community Council Directive of 24 November 1986 on the protection of animals used for experimental purposes $(86 / 609 / E E C)$. The experimental protocols were carried out in compliance with institutional ethical committee guidelines for animal research. All efforts were made 
to minimize the number of animals used and their suffering. When paralysis started, food and water were placed directly into the cage. To reduce animal pain, mice were killed when they were unable to right themselves within $30 \mathrm{~s}$ when placed on their back.

Antibodies. Antibodies used were anti-tubulin and anti-GFAP and anti-VAChT (1:1000; Sigma-Aldrich, St. Louis, MO, USA), anti-Met ${ }^{\mathrm{KD}}(1: 1000)$ and antiphospho Y1234-1235-Met (1:50; Cell Signaling, Danvers, MA, USA), anti-human Met (1:500; Santa-Cruz Biotechnology Inc., Santa Cruz, CA, USA), anti-Smi32 (1:500; Sternberger monoclonals, Covance, Dallas, TX, USA), anti-NeuN $(1: 200$; Chemicon, Millipore, Billerica, MA, USA), and anti-neurofilament-145 (1:1000; AB1987; Millipore), anti-mouse or rabbit fluorescent-coupled secondary antibodies (1:400; Jackson, West Grove, PA, USA), anti-mouse or rabbit biotin-coupled secondary antibodies (1:500; Jackson). For western blot analyses, the following secondary antibodies were used: anti-rabbit IgG-peroxidase or anti-mouse IgGperoxidase (1:4000, Jackson).

Histological analysis. Anesthetized mice were intra-cardiacally perfused first with PBS then with $4 \%$ para-formaldehyde (PFA, Sigma) in PBS. Brains, spinal cords, and muscles were dissected, postfixed in 4\% PFA and embedded. For brain and spinal cords, 16 or 30- $\mu \mathrm{m}$ thick cryo-sections were performed (Leica, Wetzlar, Germany). In situ hybridization, immuno-histochemistry, and X-Gal staining were performed as previously described. ${ }^{27,35,36} \mathrm{MN}$ numbers were determined on $16-\mu \mathrm{m}$ thick lumbar spinal cord sections stained with VAChT antibodies or cresyl violet. A total of 10 sections per mouse were analyzed. Astrogliosis was monitored by measuring fluorescence-levels of sections stained with anti-GFAP antibodies (Image J software, ImageJ 1.41, NIH, Bethesda, MD, USA). For NMJ staining, $35-\mu \mathrm{m}$ thick longitudinal sections were collected on Superfrost Plus Slides (CML, Thermo Scientific, Braunscheweig, Germany). Tissue sections were incubated in blocking solution (0.5\% Triton X-100, $5 \%$ BSA in PBS) at $37^{\circ} \mathrm{C}$ for $2 \mathrm{~h}$. Rabbit polyclonal anti neurofilament-145 antibodies were diluted in the same blocking solution and incubated overnight at $4^{\circ} \mathrm{C}$. Anti-rabbit-alexa 488-conjugated secondary antibody (Invitrogen, Life Technologies, Carlsbad, CA, USA) and $\alpha$-bungarotoxin-tetramethylrhodamine-conjugate (1:1000; Invitrogen) were incubated for $2 \mathrm{~h}$ at room temperature (1\% BSA in PBS), before washing and mounting. Stained end-plates on sections were examined under an Axio microscope (Zeiss, Oberkochen, Germany). Innervated (yellow) or denervated (red) end-plates were counted on apoptome (Zeiss) $35-\mu \mathrm{m}$ Z-stacks.

Biochemical studies. Protein extracts were prepared from freshly dissected brains and spinal cords at the appropriate stages and western blot analyses were performed as previously described. ${ }^{37-39}$ Quantifications were done by measuring band intensities with the Image $\mathrm{J}$ software.

Cultures. Cell culture procedures were previously described ${ }^{40}$ Briefly, E12.5 spinal cords from R26 LacZ-stop-Met transgenic embryos were dissected in Hank's Balanced Salt Solution containing $7 \mathrm{mM}$ HEPES pH7.4 and $4.5 \mathrm{~g} / \mathrm{l}$ glucose. Cells were dissociated in Ham-F10 medium (Invitrogen) with $0.025 \%$ Trypsin (Sigma) and centrifuged over a $4 \%$ (w/v) BSA cushion at $800 \times g$ for 5 min. Cells were plated on poly-ornithine/laminin-treated coverslips in supplemented Neurobasal medium (Invitrogen) containing neurotrophic factors $(0.1 \mathrm{ng} / \mathrm{ml}$ GDNF, $1 \mathrm{ng} / \mathrm{ml} \mathrm{BDNF}$, and $10 \mathrm{ng} / \mathrm{ml} \mathrm{CNTF}$ ) and maintained at $37^{\circ} \mathrm{C}$ in $7.5 \% \mathrm{CO}_{2}$ atmosphere for 3 days before being processed for immunochemistry. Astrocytes were prepared from P2 $R 26^{\text {LacZ-stop-Met }}$ spinal cords. When confluent, cells were trypsinized and plated onto coverslips in Dulbecco's modified Eagle's (DMEM, Invitrogen) medium supplemented with $10 \%$ fetal bovine serum and penicillin-streptomycin. Cells were then cultured at $37^{\circ} \mathrm{C}$ in $5 \% \mathrm{CO}_{2}$ atmosphere for 3 days before immunostaining. Cultured cells were processed for immunocytochemistry as above described. We used the following primary antibodies diluted in PBS containing 4\% BSA, $2 \%$ donkey serum: anti- $\beta$-Gal ( $1: 4000$; Cappel, MP Biomedicals, Ullkirch, France), antineurofilament 160 (1:600; NN18, Sigma), anti-GFAP (1:500; MAB360, Millipore). Alexa Fluor 488 (1:500; A21206; Invitrogen) and 555 (1:1000; A31570; Invitrogen)-conjugated donkey anti-rabbit and anti-mouse were used as secondary antibodies (Invitrogen).

Behavioural tests. Body weight measurements and all behavioural tests began when mice reached the age of 70 days and recording was performed weekly. To analyze motor functions, locomotor tests included the rotarod, the $1 \mathrm{~m}$ swimming tank and the footprint, which have been done as previously described. ${ }^{27} \mathrm{We}$ performed four trials at each time point for each animal and recorded the three best performances for statistical analysis. Briefly, the rotarod test was performed by placing mice on an accelerating rod ( $3 \mathrm{~cm}$ diameter) and by recording the time each animal took to fall from the rod. The speed of the rotarod accelerated from 4 to 40 r.p.m. over a 5-min period. The swimming tank device allows evaluation of the hindlimb strength and performance; it is suitable for assessing onset and progression of ALS symptoms. For the swimming tank, each mouse performed four trials and the time needed to reach the platform was recorded. A mouse was considered at the onset of motor defect when it needed $6.8 \mathrm{~s}$ to perform the swimming tank test. The $6.8 \mathrm{~s}$ were chosen as reference as this value corresponds to the first significant difference versus control mice. For the footprint test, the foretoes and the hind-toes were labelled in blue and red, respectively. Weekly monitoring of walking patterns allows assessment of motor coordination and synchrony through the evaluation of several parameters, including toe spread, forepaw/hindpaw overlap, and step-length. Two parameters were measured: (1) the overlap distance between forepaw and hindpaw on the same side; (2) the stride length as the distance of the hindpaw on the same side between each step. For the overlap, the Kaplan-Meier curve indicates the mice when the distance between forepaw and hindpaw increased by $45 \%$. For the step length, the Kaplan-Meier curve indicates when the distance of the hindpaw for each step decreased by $40 \%$. To reduce mouse stress and fatigue, the swimming and the footprint behavioural tests were carried out on different days.

Statistical analysis. Results were expressed as the mean \pm S.E.M. Statistically significant differences on cell counts were assessed by the Student's $t$-test. Statistically significant differences among the groups of mice were assessed by two-way ANOVA. Post hoc Bonferroni's correction was also used to test all pairwise comparisons between groups and time points per group. A log-rank test was used to calculate the statistical differences in the onset and survival of the different mouse cohorts. Statistical significance was defined as ns: $P>0.05$; ${ }^{*} P<0.05$; ${ }^{\star \star} P<0.01 ;{ }^{* \star} P<0.001$.

\section{Conflict of interest}

The authors declare no conflict of interest.

Acknowledgements. We are particularly grateful to $C$ Henderson, A Mogrich, $\mathrm{K}$ Dudley, and all lab members for discussions and comments. We thank: V GirodDavid, L Jullien, staff members at IBDML and CIML animal house and transgenic facilities for help with mouse husbandry; IBDML imaging platform; CG Lobe for the pCALL2 vector. This work was supported by funds from INCa, ARC, FRM, AFM, FdF, Fondation Bettencourt-Schueller, Marie Curie Host Fellowship for the Transferof-Knowledge to FM and RD. MG was supported by University-Franco-Italy fellowship, EC by AFM, AF by FRM, HH by FdF, ARC.

1. Lemmon MA, Schlessinger J. Cell signaling by receptor tyrosine kinases. Cell 2010; 141: 1117-1134.

2. Maina F, Pante G, Helmbacher F, Andres R, Porthin A, Davies AM et al. Coupling Met to specific pathways results in distinct developmental outcomes. Mol Cell 2001; 7: 1293-1306.

3. Furlan A, Stagni V, Hussain A, Richelme S, Conti F, Prodosmo A et al. Abl interconnects oncogenic Met and p53 core pathways in cancer cells. Cell Death Differ 2011 in press.

4. Connor B, Dragunow M. The role of neuronal growth factors in neurodegenerative disorders of the human brain. Brain Res Brain Res Rev 1998; 27: 1-39.

5. Snider WD, Zhou FQ, Zhong J, Markus A. Signaling the pathway to regeneration. Neuron 2002; 35: 13-16.

6. Siegel GJ, Chauhan NB. Neurotrophic factors in Alzheimer's and Parkinson's disease brain. Brain Res Brain Res Rev 2000; 33: 199-227.

7. Kanning KC, Kaplan A, Henderson CE. Motor neuron diversity in development and disease. Annu Rev Neurosci 2010; 33: 409-440.

8. Boillee S, Yamanaka K, Lobsiger CS, Copeland NG, Jenkins NA, Kassiotis G et al. Onset and progression in inherited ALS determined by motor neurons and microglia. Science 2006; 312: 1389-1392.

9. Yamanaka K, Chun SJ, Boillee S, Fujimori-Tonou N, Yamashita H, Gutmann DH et al. Astrocytes as determinants of disease progression in inherited amyotrophic lateral sclerosis. Nat Neurosci 2008; 11: 251-253.

10. Miller TM, Kaspar BK, Kops GJ, Yamanaka K, Christian LJ, Gage FH et al. Virus-delivered small RNA silencing sustains strength in amyotrophic lateral sclerosis. Ann Neurol 2005; 57: 773-776. 
11. Ralph GS, Radcliffe PA, Day DM, Carthy JM, Leroux MA, Lee DC et al. Silencing mutant SOD1 using RNAi protects against neurodegeneration and extends survival in an ALS model. Nat Med 2005; 11: 429-433.

12. Gould TW, Buss RR, Vinsant S, Prevette D, Sun W, Knudson CM et al. Complete dissociation of motor neuron death from motor dysfunction by Bax deletion in a mouse model of ALS. J Neurosci 2006; 26: 8774-8786.

13. Guillot S, Azzouz M, Deglon N, Zurn A, Aebischer P. Local GDNF expression mediated by lentiviral vector protects facial nerve motoneurons but not spinal motoneurons in SOD1(G93A) transgenic mice. Neurobiol Dis 2004; 16: 139-149.

14. Li W, Brakefield D, Pan Y, Hunter D, Myckatyn TM, Parsadanian A. Muscle-derived but not centrally derived transgene GDNF is neuroprotective in G93A-SOD1 mouse model of ALS Exp Neurol 2007; 203: 457-471.

15. Maina F, Hilton MC, Andres R, Wyatt S, Klein R, Davies AM. Multiple roles for hepatocyte growth factor in sympathetic neuron development. Neuron 1998; 20: 835-846.

16. Maina $F$, Klein R. Hepatocyte growth factor-a versatile signal for developing neurons. Nat Neurosci 1999; 2: 213-217.

17. Ebens A, Brose K, Leonardo ED, Hanson MG, Bladt F, Birchmeier C et al. Hepatocyte growth factor/Scatter factor is an axonal chemoattractant and a neurotrophic factor for spinal motor neurons. Neuron 1996; 17: 1157-1172.

18. Maina F, Hilton MC, Ponzetto C, Davies AM, Klein R. Met receptor signaling is required fo sensory nerve development and HGF promotes axonal growth and survival of sensory neurons. Genes Dev 1997; 11: 3341-3350.

19. Yamamoto Y, Livet J, Pollock RA, Garces A, Arce V, deLapeyriere $O$ et al. Hepatocyte growth factor (HGF/SF) is a muscle-derived survival factor for a subpopulation of embryonic motoneurons. Development 1997; 124: 2903-2913.

20. Helmbacher F, Dessaud E, Arber S, deLapeyriere O, Henderson CE, Klein R et al. Met signaling is required for recruitment of motor neurons to PEA3-positive motor pools. Neuron 2003; 39: 767-777.

21. Kato N, Nemoto $\mathrm{K}$, Nakanishi $\mathrm{K}$, Morishita $\mathrm{R}$, Kaneda $\mathrm{Y}$, Uenoyama $\mathrm{M}$ et al. Nonviral HVJ (hemagglutinating virus of Japan) liposome-mediated retrograde gene transfer of human hepatocyte growth factor into rat nervous system promotes functional and histological recovery of the crushed nerve. Neurosci Res 2005; 52: 299-310.

22. Kitamura K, Iwanami A, Nakamura M, Yamane J, Watanabe K, Suzuki Y et al. Hepatocyte growth factor promotes endogenous repair and functional recovery after spinal cord injury. J Neurosci Res 2007; 85: 2332-2342.

23. Sun W, Funakoshi H, Nakamura T. Overexpression of HGF retards disease progression and prolongs life span in a transgenic mouse model of ALS. $J$ Neurosci 2002; 22 $6537-6548$.

24. Kadoyama K, Funakoshi H, Ohya W, Nakamura T. Hepatocyte growth factor (HGF) attenuates gliosis and motoneuronal degeneration in the brainstem motor nuclei of a transgenic mouse model of ALS. Neurosci Res 2007; 59: 446-456.

25. Tronche F, Kellendonk C, Kretz O, Gass P, Anlag K, Orban PC et al. Disruption of the glucocorticoid receptor gene in the nervous system results in reduced anxiety. Nat Genet 1999; 23: 99-103.

26. Soriano P. Generalized lacZ expression with the ROSA26 Cre reporter strain. Nat Genet 1999; 21: 70-71.
27. Raoul C, Abbas-Terki T, Bensadoun JC, Guillot S, Haase G, Szulc J et al. Lentiviralmediated silencing of SOD1 through RNA interference retards disease onset and progression in a mouse model of ALS. Nat Med 2005; 11: 423-428.

28. Huh CG, Factor VM, Sanchez A, Uchida K, Conner EA, Thorgeirsson SS. Hepatocyte growth factor/c-met signaling pathway is required for efficient liver regeneration and repair. Proc Natl Acad Sci USA 2004; 101: 4477-4482.

29. Chmielowiec J, Borowiak M, Morkel M, Stradal T, Munz B, Werner S et al. c-Met is essential for wound healing in the skin. J Cell Biol 2007; 177: 151-162.

30. Ishigaki A, Aoki M, Nagai M, Warita $\mathrm{H}$, Kato $\mathrm{S}$, Kato $\mathrm{M}$ et al. Intrathecal delivery of hepatocyte growth factor from amyotrophic lateral sclerosis onset suppresses disease progression in rat amyotrophic lateral sclerosis model. J Neuropathol Exp Neurol 2007; 66: 1037-1044.

31. Bladt F, Riethmacher D, Isenmann S, Aguzzi A, Birchmeier C. Essential role for the c-met receptor in the migration of myogenic precursor cells into the limb bud. Nature 1995; 376 : 768-771

32. Maina F, Casagranda F, Audero E, Simeone A, Comoglio P, Klein R et al. Uncoupling of Grb2 from the Met receptor in vivo reveals complex roles in muscle development. Cell 1996; 87: 531-542.

33. Madhavan R, Peng HB. HGF induction of postsynaptic specializations at the neuromuscular junction. J Neurobiol 2006; 66: 134-147.

34. Chiu AY, Zhai P, Dal Canto MC, Peters TM, Kwon YW, Prattis SM et al. Age-dependent penetrance of disease in a transgenic mouse model of familial amyotrophic lateral sclerosis. Mol Cell Neurosci 1995; 6: 349-362.

35. Dono R. Fibroblast growth factors as regulators of central nervous system development and function. Am J Physiol Regul Integr Comp Physiol 2003; 284: R867-R881.

36. Zuniga A, Michos O, Spitz F, Haramis AP, Panman L, Galli A et al. Mouse limb deformity mutations disrupt a global control region within the large regulatory landscape required for Gremlin expression. Genes Dev 2004; 18: 1553-1564.

37. Segarra J, Balenci L, Drenth T, Maina F, Lamballe F. Combined Signaling through ERK, $\mathrm{PI} 3 \mathrm{~K} / \mathrm{AKT}$, and RAC1/p38 Is Required for Met-triggered Cortical Neuron Migration. J Bio Chem 2006; 281: 4771-4778.

38. Moumen A, leraci A, Patane S, Sole C, Comella JX, Dono R et al. Met signals hepatocyte survival by preventing Fas-triggered FLIP degradation in a PI3k-Akt-dependent manner. Hepatology 2007; 45: 1210-1217.

39. Moumen A, Patane S, Porras A, Dono R, Maina F. Met acts on Mdm2 via mTOR to signal cell survival during development. Development 2007; 134: 1443-1451.

40. Aebischer J, Cassina P, Otsmane B, Moumen A, Seilhean D, Meininger V et al. IFNgamma triggers a LIGHT-dependent selective death of motoneurons contributing to the non-cellautonomous effects of mutant SOD1. Cell Death Differ, e-pub ahead of print 12 November 2010.

Cell Death and Disease is an open-access journal published by Nature Publishing Group. This work is licensed under the Creative Commons Attribution-Noncommercial-No Derivative Works 3.0 Unported License. To view a copy of this license, visit http://creativecommons.org/licenses/by-nc-nd/3.0/

Supplementary Information accompanies the paper on Cell Death and Disease website (http://www.nature.com/cddis) 